Relatorio

\title{
A PAISAXE COMO INSTITUCIÓN DA REALIDADE
}

Augustin Berque

EHESS/CNRS, Paris 



\section{FALANDO DA PAISAXE}

Aínda que a humanidade comproba acotío que as traducións non sempre son posibles, os científicos sociais, que teoricamente coñecen a hipótese Sapir-Whorf, adoitan subestimar a incidencia práctica dos problemas lingüísticos nos seus propios obxectos de estudo. A paisaxe é un exemplo disto. Moitas das controversias xurdidas nos últimos anos arredor deste concepto teñen a súa orixe no feito de que as persoas, sinxelamente, non falan da mesma cousa cando debaten sobre a paisaxe. Isto pode acontecer entre xente que se expresa na mesma lingua, así que, con máis razón, ocorre cando as linguas non coinciden. Obviando os falantes que pertencen a ámbitos culturais completamente distintos -como na hipótese Sapir-Whorf-, esta situación é facilmente observable mesmo entre dúas linguas de familias máis próximas, como o inglés e o francés. A palabra landsca$p e$ realmente equivale a paysage? Só en certa forma. Desde o punto de vista lingüístico, a verdade é que estas dúas palabras se formaron dun xeito bastante diferente. Seguindo a regra das linguas xermánicas, en landscape o determinante é land. De feito, no alemán antigo Landschaft - na escrita actual- era orixinariamente unha forma de organización territorial. Non foi ata o Renacemento cando adquiriu o significado dunha representación do territorio, derivado de Landschaftsbild -imaxe da Landschaft. Deste proceso dedúcese que primeiro existe a realidade do territorio: Landschaft, e despois unha representación deste: Landschaft [sbild]. Nas linguas románicas deuse o proceso inverso. Paysage derivaría de pays (terra, país), pero era un neoloxismo acuñado por pintores no século XVI, cuxo significado orixinario era a imaxe en si mesma e non o territorio. Este proceso implica que primeiro se ten a representación e, en segundo lugar, o que se representa, é dicir, o territorio. De feito, só foi máis tarde cando, metonimicamente, paysage veu a significar non só unha imaxe, senón tamén o territorio que se pode pintar ou contemplar. 
Esta cuestión vai máis alá do eido da lexicoloxía. Resulta evidente que, mesmo na actualidade, o tema da paisaxe non é igual na literatura inglesa e na francesa. Aquela mostra unha tendencia a centrarse no obxecto representado, mentres que esta se centra na representación dese obxecto. Un bo exemplo desta diferenza de perspectiva é a distinción entre natural landscape e cultural landscape que popularizaron Carl Sauer e a escola de Berkeley e que é actualmente empregada oficialmente por institucións como a UNESCO. Para moitos estudosos franceses, incluído o autor deste artigo, a devandita distinción é un oxímoro, posto que calquera paisaxe implica a representación -que abrangue a percepción e a concepción- dun territorio determinado e, xa que logo, é necesariamente cultural. Pola mesma razón, supoño, obsérvase na literatura inglesa unha tendencia a «naturalizar» a paisaxe -é dicir, a considerala o territorio mesmo sobre o que se pode falar-, mentres que na literatura francesa se tende a insistir na relatividade cultural da paisaxe. Así, ao longo de todo o monumental estudo de Clarence J. Glacken, Traces on the Rhodian shore (1967), a palabra landscape é empregada no mesmo sentido, o dun ambiente obxectivo e independente das diversas etapas culturais que se sucederon unha tras da outra no mundo occidental desde a Antigüidade e que comportaban actitudes moi diversas cara ao medio natural. Pola contra, a influencia da fenomenoloxía, no tocante á cuestión da paisaxe na literatura francesa, supuxo unha clara distinción entre paisaxe e medio natural, sobre todo a partir dos anos setenta. Lembro unha conversa que mantiven cun colega estadounidense nun simposio celebrado en Quioto en 1992, na que acabei por decatarme de que estabamos a empregar estas dúas palabras cun sentido practicamente oposto. Para el, landscape (paisaxe) significaba unha realidade obxectiva e environment (medio natural) algo necesariamente fenomenolóxico, e para min era todo o contrario.

Fóra de malentendidos, o caso é que no último cuarto de século a historicidade da paisaxe foi moito máis cuestionada no Continente que na Angloesfera. Na historia da arte non é nin moito menos unha novidade que o xénero da pintura paisaxística non existía na Idade Media en Europa: apareceu no Renacemento e foi nomeado posteriormente con palabras que querían dicir "paisaxe» que ou ben non existían ou non tiñan ese sentido na Idade Media. Con todo, non foi ata hai moi pouco cando este feito histórico fixo que nos preguntásemos realmente que é a paisaxe. Ata daquela, a ninguén lle preocupou a evidente 
incompatibilidade entre esta "historicidade fenoménica» - manifesta na arte e na linguaxe- da paisaxe, por unha banda, e, pola outra, a súa "universalidade física» como a forma dunha parte dada do territorio, sendo esta última acepción un trazo importante de disciplinas como a xeografía -particularmente en Alemaña, onde se denomina Landschafskunde, á «ciencia da paisaxe». Esta falta de preocupación reflíctese exemplarmente no estudo de Glacken, que, malia ser un minucioso relato sobre a percepción e consideración da natureza ata os nosos días no mundo occidental, non ten en conta a historicidade do concepto de "paisaxe». Quizais foi Joachim Ritter (Ritter, 1963) o primeiro en considerar esta historicidade como un problema real. A súa tese consistía en que o xurdimento da paisaxe foi unha compensación razoable da obxectivación do medio natural por parte da ciencia moderna; é dicir, mantivo unha unidade cosmolóxica entre o que o dualismo dividira nos dous mundos do subxectivo e do obxectivo. $\mathrm{O}$ certo é que, como xa expliquei noutros traballos (Berque, 2006), esta tese é escandalosamente anacrónica, pero esta non é a cuestión que nos ocupa. Ao Landschaft de Ritter seguíronlle varios traballos que, paseniño, aclararon que a «paisaxe» daquel estudo poida que non fose tal: é unha especie de relación entre a sociedade e o seu medio natural, que na cultura occidental apareceu nun determinado momento da Historia e que non existe en todas as culturas. No seu libro El Paisaje. Genealogía de un concepto, Javier Maderuelo (Maderuelo, 2006) ofrece unha boa síntese deste problema.

Con todo, estes progresos non acabaron coa ambivalencia da palabra "paisaxe». Para as ciencias naturais, como a ecoloxía da paisaxe, segue a ser a forma obxectiva dunha determinada parte da superficie terrestre, teoricamente independente do observador e, xa que logo, non relacionada coa cultura, agás polas consecuencias materiais da antropización. Nas ciencias sociais atopamos toda clase de acepcións, desde a anterior -é dicir, a paisaxe como a forma obxectiva dun ambiente- ata a idea de que a paisaxe é fundamentalmente unha representación construída -«inventada»- social e historicamente. Esta confusión fai que, mesmo entre aqueles que admiten a historicidade de "paisaxe», poucos concorden sobre a súa historia. Moi debatida, por exemplo, é a cuestión de se os romanos tiñan ou non este concepto.

Moitas destas controversias débense á falta de criterios obxectivos para definir o que entendemos por «paisaxe». Pola miña parte, nos últimos vinte anos 
empreguei empiricamente catro, ao principio, e finalmente sete deses criterios. Se non se cumpre ningún destes criterios, coido que falar de "paisaxe» é utilizar mal o termo -polo menos nas ciencias sociais. Estes son, concretamente, os devanditos criterios, dos menos aos máis discriminatorios: 1) Literatura -oral ou escrita-, que canta a beleza dun ambiente. 2) Topónimos en que hai implícita unha valoración visual do ambiente -por exemplo nos franceses Bellevue, Mirabeau, etc. 3) Xardíns do pracer. 4) Arquitectura creada para apreciar as vistas -por exemplo balcóns, balconadas, etc. 5) Representacións pictóricas da paisaxe. 6) Unha ou varias palabras para designar «paisaxe». 7) Reflexións explícitas sobre o tema da paisaxe.

\section{O NACEMENTO DA PAISAXE}

Segundo as condicións anteriores, foi no sur da China, cara ao século V d. de C., cando a paisaxe apareceu por primeira vez na historia da humanidade. A obra de Zong Bing Hua shanshui xu (Introdución á pintura paisaxistica) foi escrita arredor do ano 440. Nela atopamos unha reflexión explícita sobre a natureza da paisaxe -shanshui-, resumida na enunciación dun principio -o de Zong Bing, como eu o chamo- que, como se verá máis adiante, aínda se pode considerar o quid do problema da paisaxe. Zong Bing (375-443) era pintor e a aparición da pintura de paisaxes na China adoita asociarse ás obras do seu contemporáneo, aínda que máis vello ca el, Gu Kaizhi (ca. 346-ca. 406), autor, entre outras cousas, dunha escala en que este xénero se considera menos difícil que pintar persoas e máis que pintar animais, arquitectura e utensilios de uso corrente (Escande, 2005 , p. 80 e ss.). A existencia en si do concepto de "paisaxe» queda testemuñada no ano 353 en Lanting yan ji (Recompilación do banquete no Pavillón das Orquideas), unha antoloxía en que se lembra un suceso ao que volverei no final deste artigo. O devandito testemuño é a palabra shanshui, que aparece no seguinte dístico do célebre calígrafo Wang Xizhi:

散懷山水 San huai shanshui Distraendo o meu pesadume na paisaxe 蕭然忘羈 Xiaoran wang ji Sen decatarme, esquezo o meu cabestro 
ou tamén, de Sun Tong:

地主観山水 Dizhu guan shanshui

仰尋幽人踪 Yang xun you ren zong
O señor da terra observa a paisaxe na procura das pegadas de eremitas ${ }^{1}$

Con todo, a palabra shanshui, que é moito máis antiga, non sempre significou «paisaxe». Derívase de dúas palabras, shan 水, montaña; e shui 山, auga, río; cada unha das cales é, loxicamente, moi antiga. Estas dúas palabras únense por primeira vez nunha, shanshui, contra finais do período dos Estados en Guerra (475-221 a. de C.), pero este novo vocábulo non significa «paisaxe». Máis ben designa os regatos de montaña e é usado principalmente entre os enxeñeiros para falar do control de inundacións e da rega. Non ten nada que ver coa estética. Podémola atopar na poesía de só uns séculos despois, na obra Zhao yinshi shier shou (Doce odas ao convite dun eremita), de Zuo Si (ca. 250-305). No primeiro destes poemas pode lerse o seguinte verso:

山水有清音 Shanshui you qing yin As augas da montaña teñen un son puro²

polo que non é preciso, dise no verso anterior, usar instrumentos musicais. Aquí vese claramente que shanshui fai referencia a un torrente, non á paisaxe. Pero igualmente obvio é que esta palabra adquiriu unha connotación estética e nas décadas seguintes, precisamente pola influencia dos poemas de Zuo Si, o seu significado primario evoluciona á acepción moderna de "paisaxe». Os dísticos recollidos en Lanting, en 353, son froito desta evolución.

Isto non ocorreu en Roma. Malia que sabemos que os romanos apreciaban a beleza do medio natural, non crearon a noción de paisaxe e, por non teren unha palabra para nomeala, non deixaron ningunha reflexión sobre este tema. Ao meu ver, isto é debido a que non relacionaron topia ou topiaria opera, que designan as formas ornamentais de herba cortada dos xardíns ou os motivos paisaxísticos nos frescos - no sentido dado por Vitruvio en De Architectura-; e amoenia, loca amoena ou amoenitas locorum, que designan o grato ou pracenteiro de cer-

\footnotetext{
${ }^{1}$ Estes poemas cítanse en Gotô, 2000, p. 81-82, que tamén é a miña referencia principal para a historia da palabra shanshui.

${ }^{2}$ Pódese ler o poema completo en Gotô, 2000, p. 79-80.
} 
tos lugares no ambiente exterior -en Cicerón, De Oratore. Noutras pala- bras, seguiu existindo unha lagoa entre o territorio e a súa representación, xustamente o que se uniría no Renacemento para dar lugar ao concepto moderno de paisaxe. Esta lagoa mental está simbolizada polo feito de que as villae romanas, aínda que se construísen no medio das paisaxes máis fermosas e con topia nas paredes, permaneceron orientadas cara ao atrium, sen vistas á paisaxe do arredor ${ }^{3}$.

Por este motivo, a coñecida pasaxe seguinte de Cartas, de Plinio fillo: «Regionis forma pulcherrima [...]. Neque enim terras tibi, sed formam aliquam ad eximiam pulchritudinem pictam videberis cernere», non quere dicir que Plinio celebrase a paisaxe como tal, aínda que a maioría dos tradutores empreguen esta palabra. O que escribe, sendo estritos, é que «o aspecto da rexión é marabilloso [...]. Diríase que o que se ve non é unha terra [real], senón unha forma pintada de suma beleza».

A palabra «forma» é demasiado xeral para traducila por "paisaxe». O que se pode deducir da distinción de Plinio entre terra e forma picta é xustamente que as formas da terra, en si mesmas, non están inseridas necesariamente nunha paisaxe. Precísase algo máis: a consciencia de estar gozando da paisaxe en si, é dicir, algo en que as formas da terra e as representacións constitúen unha entidade harmónica para o gozo estético, expresándoo cunha palabra, "paisaxe».

Pola contra, isto é o que se di explicitamente sobre shanshui nos dous exemplos seguintes. $\mathrm{O}$ primeiro son dous versos extraídos dun poema ${ }^{4}$ de Xie Lingyun (385-433), o primeiro "poeta paisaxístico» (shanshui shiren):

情用賞為美 Qing yong shang wei mei Sentir, por medio do gusto, crea a beleza 事昧竟誰辨 Shi meijing shei bian Cousa escura ata que alguén a expresa

o que significa que a beleza dunha paisaxe non reside unicamente nas formas da terra, senón na maneira de contemplalas, o que require certo gusto (shang). Isto, e mais as palabras para expresalo claramente (bian), é o que "fai fermosas» (wei mei) estas formas da terra.

\footnotetext{
${ }^{3}$ Sobre a importancia da arquitectura nestes asuntos, véxase especialmente Maderuelo, 2005.

${ }^{4}$ Cita de Obi, 1983, p. 114-115.
} 
Por suposto, o shang necesario non é universal. Só o posúen uns poucos privilexiados, unha elite equivalente á «clase do lecer» de Veblen. Xa que logo, para apreciar unha paisaxe en si mesma non é preciso labrar a terra, como aclarou Raymond Williams (Willians, 1973). Esta lóxica social é o que eu denomino o «principio de Xie Lingyun». Pero este non é o asunto que nos ocupa. O que realmente importa é que a realidade dunha paisaxe non se limita á materialidade das formas da terra, o que eu chamo o "principio de Zong Bing», xa que nas primeiras liñas da súa Introdución á pintura paisaxística consta claramente o seguinte:

\section{至於山水、質有而趣霊 Zhi yu shanshui, zhi you er qu ling}

Canto á paisaxe, aínda que posúe unha forma material, tende ao espiritual ${ }^{5}$.

E este é o verdadeiro núcleo do problema da paisaxe. Por unha banda, a paisaxe é un obxecto material do exterior e, pola outra, require unha certa predisposición mental por parte do espectador. Ou sexa, a realidade da paisaxe reside na relación entre estes dous polos teóricos. Para captar esta realidade é necesario o que chamarei un "enfoque mesolóxico» da paisaxe.

\section{MESOLOXÍA}

A palabra mésologie (mesoloxía) foi acuñada arredor de 1869 por Louis-Adolphe Bertillon, un médico, estatístico e demógrafo que, segundo se cre, non lle daba o sentido co que Ernst Haeckel definiu a Ökologie (ecoloxía) un pouco antes, en 1867. O significado que lle daba Bertillon era máis amplo, xa que abranguía a vida e a organización das sociedades humanas. Ademais, esta debe ser unha das razóns polas que a palabra "mesoloxía» non prosperou tanto como «ecoloxía» e foi, xa que logo, desaparecendo progresivamente dos dicionarios, malia que foi obxecto dun tratamento detallado na primeira edición do dicionario Grand Larousse du XIX siècle. De feito, o destino da mesoloxía non chegou a cumprirse, que puido ser abarcar os dous ámbitos do que posteriormente sería a socioloxía, por un lado, e a ecoloxía, polo outro. Naquela época, este ámbito de estudo

\footnotetext{
${ }^{5}$ Pódese atopar o texto completo en Delahaye, 1981, p. 84 e ss.
} 
superaba con moito a capacidade dunha soa disciplina. $\mathrm{Na}$ actualidade, malia que mésologie non desapareceu totalmente no francés, as súas acepcións correntes convértena en pouco máis que un sinónimo pouco común -empregado rara vez ou nunca, unha subvariante- de «ecoloxía» e xa non ten ningunha relación coas ciencias sociais.

Desenterrei esta palabra hai vinte anos (Berque, 1986) para traducir o termo fûdogaku 風土学 de Watsuji Tetsurô ${ }^{6}$ (Watsuji, 1935), cuxo significado é o estudo do medio humano -entendendo aquí «medio», en xaponés fûdo 風土, como a relación entre unha sociedade e o seu medio natural. Inspirado por Heidegger, que asemade o fixera en Uexküll (Agamben, 2002), Watsuji estableceu unha distinción decisiva entre ambientes naturais (shizen kankyô 自然環境), obxecto de estudo das ciencias naturais, e medios humanos (fûdo 風土), que, segundo a súa definición, teñen o ser humano como centro e, xa que logo, requiren unha aproximación hermenéutica.

Malia que Watsuji non menciona a Uexküll, a súa distinción entre ambiente e medio é homóloga á que fai o naturalista alemán, precursor da etioloxía, entre Umgebung (os datos obxectivos do ambiente) e Umwelt (o mundo propio dunha determinada especie). Volveremos a esta cuestión posteriormente. Polo de agora, formularemos esta homoloxía como se indica:

\section{Umgebung/Umwelt : kankyô (ambiente)/fûdo (medio).}

Con todo, hai unha diferenza entre ambos os dous pares de palabras: a distinción entre o primeiro par establécese no nivel ontolóxico da biosfera -no espazo- e da evolución -no tempo-, mentres que a distinción entre o segundo par de palabras se establece no tempo correspondente da historia e no espazo da ecúmene, que integra non só os ecosistemas senón, sobre todo, os sistemas técnicos e simbólicos propios do xénero humano: é «medial»ou "mesolóxica», é dicir, eco-tecno-simbólica, mentres que a primeira é só ecolóxica. Por este motivo, igual que a biosfera -que presupón a existencia de vida- é ontoloxicamente superior ao planeta -que é só un sistema físico-químico-, a ecúmene é ontoloxicamente superior á biosfera, que é, por dicilo así, a súa materia prima. No

\footnotetext{
${ }^{6} \mathrm{Na}$ orde habitual xaponesa, e tamén na chinesa, o apelido vai en primeiro lugar.
} 
tocante aos medios humanos -que constitúen conxuntamente a ecúmene-, ao estaren antropizados por sistemas técnicos e humanizados por sistemas simbólicos, non poden quedar reducidos aos ecosistemas do ambiente (Umgebung); son o Umwelt específico do ser humano. É dicir, que lle engaden a cultura á natureza. Da mesma maneira, non poden quedar reducidos á evolución: pertencen especificamente á historia.

A este nivel ontolóxico, historicamente, apareceu e despois desenvolveuse a paisaxe. Dado que para moitos a paisaxe segue a ser, por dicilo así, un Umgebung visible -o que é un oxímoro-, cómpre repetir que, no tocante aos seres humanos, non se pode falar con propiedade de "paisaxe» se non se cumpren os sete criterios dos que falamos anteriormente. Por non dicir que «paisaxe» só existe no léxico dos falantes occidentais de hoxe e non na realidade histórica ou exótica en cuestión.

Neste punto, xorde unha dupla pregunta: que había «antes» do nacemento da paisaxe? E cal é a natureza do seu proceso de nacemento?

A primeira parte é o mesmo que preguntar como se percibe o ambiente nas sociedades «non paisaxísticas». Supoñendo que todas as sociedades humanas posúen un mundo humano como tal (Umwelt), a resposta é que cada unha delas ten a súa forma particular de percibir a realidade dese mundo -isto non debe confundirse cun ambiente universal (Umgebung). Xa que logo, a nosa misión -a das ciencias sociais- consiste en caracterizar o xeito particular de percepción dunha ou doutra sociedade, nesta ou naquela época da historia, por exemplo, analizando o léxico relativo ao ambiente. Evidentemente, existen tantos casos como hai ou houbo culturas na historia da humanidade. Percibir o ambiente como paisaxe é un deles. Noutras palabras, a «paisaxe» é unha variedade, dun proceso máis xeral, específica dun medio dado.

Agora ben, cal é a natureza dese proceso xeral? E como evolucionou a esta variedade, a paisaxe?

\section{COSMOFANÍA}

Hai uns dez anos sentín o impulso de empregar a palabra cosmophanie (Berque, 1998) porque distinguir unicamente entre «civilizacións paisaxísticas» (civilisations paysagères), como a China e a Europa moderna, e «non 
paisaxísticas» (civilisations non-paysagères), do resto do mundo, como fixera ata daquela (Berque, 1995), non era só simplificar de máis, senón que resultaba excesivamente discriminatorio. Non se podía «clasificar» unha civilización por non ter un criterio que só existía na China e na Europa moderna! No entanto, era imposible considerar todos os modos distintos en que as sociedades humanas caracterizaron a súa propia percepción do ambiente. Quedou patente, xa que logo, que se precisaba un concepto xeral que abranguese practicamente calquera dos devanditos modos de percepción. Alén disto, tendo en conta que a base universal de todos estes modos diferentes era a mundanidade humana como tal - Weltlichkeit, na terminoloxía de Heidegger ${ }^{7}$-, é dicir, o feito de ter un mundo - Welt, ou Umwelt, na terminoloxía de Uexküll-, era evidente que todos eles tiñan en común que aparecían (phainein) como a realidade "do mundo" (ho kosmos) particular de cada un. De aquí provén a palabra «cosmofanía».

Por suposto, a expresión concreta -a realidade- da cosmofanía varía en función da cultura e da historia. Podería ser, por exemplo, "paisaxe» ou outra cousa; pero o principio é o mesmo en todos os casos e resulta inherente ao feito de ser unha persoa que vive no planeta Terra.

$\mathrm{O}$ que denominei «un enfoque mesolóxico» ten como finalidade, especificamente, entender que é «realidade» nun medio humano. Neste ámbito, a cosmofanía preséntase como unha cuestión esencial. $\mathrm{Na}$ seguinte parte deste traballo exporei algunhas das claves que, paseniño, provocaron o xurdimento deste problema.

\section{VER COMO}

Un paso importante foi o meu descubrimento da palabra xaponesa mitate 見立 て. Abrir o New Japanese-English Dictionary (5a edición, 2003) pola palabra mitate non é de moita axuda, xa que só se ofrecen as seguintes acepcións: 1. Elección, selección, por exemplo, Quen elixiu esa roupa?; 2. Diagnóstico,

\footnotetext{
7 Para Heidegger, en 1935 (Heidegger, 1949) a pedra é «carente de mundo»-weltlos-, o animal é «pobre en mundo" -weltarm - e o ser humano é "conformador de mundo" -weltbildend-. Desde a perspectiva mesolóxica, isto é o mesmo que diferenciar entre planeta, biosfera e ecúmene -correspondentes, respectivamente, a procesos físicos, evolución e historia.
} 
opinión médica; 3. Valoración, xuízo; 4. Símil, comparación. A última definición derivou nun dos usos do verbo mitateru (facer unha mitate): comparar A con B, co seguinte exemplo: "Comparamos a nosa casa cun castelo cun río detrás que lle serve de foso».

Estas definicións non indican que o concepto de mitate tivese importancia na historia da estética xaponesa e, sobre todo, na dos xardíns e a paisaxe. Isto constateino na extraordinaria obra de Nakamura Yoshio Fûkeigaku nyûmon (Introdución ao estudo da paisaxe) (Nakamura, 1982). Nos xardíns, o principio de mitate consiste en deseñar un motivo que faga referencia a algunha paisaxe coñecida, como o monte Fuji ou as fervenzas de Nachi. Este principio xa se enunciara na introdución do primeiro tratado xaponés sobre a arte dos xardíns no Xapón -e tamén en Asia Oriental-, o Sakuteiki 作庭記, atribuído a Tachibana no Toshitsuna (1028-1094): «Así, farase o xardín ao tempo que se adaptan e harmonizan as formas principais (ohosugata) ás condicións locais de diversos lugares famosos (meisho), os cales un fará algo propio (waga mono)» ${ }^{8}$.

$\mathrm{Si}$, na descrición desta pasaxe non se emprega a palabra mitate -apareceu varios séculos despois-, pero o principio xa queda claro: cómpre orientar o microcosmos -o xardín- cara ao macrocosmos -o territorio-, mediante a referencia a determinados lugares coñecidos pola súa beleza panorámica ou por algunha outra razón histórica.

De feito, este principio non se lles aplica só aos xardíns, senón a calquera forma de creación estética, como son a literatura e a pintura. $\mathrm{O}$ esencial é que a mitate non se restrinxe a un único ámbito, como por exemplo facer referencia a un poema anterior na poesía, trátase, máis ben, de traspasar as fronteiras dese ámbito e facer referencia a outro 9 .

Así, por exemplo, pintar un biombo con referencias a un poema; ou, nun xardín, incluír referencias a outro lugar xeográfico real ou ficticio, tomado da literatura ou da pintura. En definitiva, trátase de relacionar un ámbito A cun ámbito B.

Para unha mellor comprensión do principio de mitate, paga a pena analizar a composición desta palabra. Consta de dous elementos: $m i$ 見, que significa ver, e tate[ru] 立て(る), que quere dicir poñer algo de pé. Polo tanto, analiticamente, ver algo de tal maneira que destaque. Por exemplo, ver un montículo

\footnotetext{
${ }^{8}$ Para máis referencias, véxase Berque, 1986, p. 196 e ss.

${ }^{9}$ Isto non ten moito que ver con ekphrasis, que non é alusivo senón descritivo.
} 
nun xardín como se fose o monte Fuji. Dito doutro xeito, crear o monte Fuji empregando un montículo.

Débese distinguir mitate dun simple sinónimo de «representación». Non é algo puramente icónico, xa que se aprecia mellor cando se cruzan as fronteiras de dous ámbitos sensoriais, como a poesía e a paisaxe. E mesmo nun só ámbito, como a paisaxe, non se basea nunha verosimilitude morfolóxica. Un dos aspectos máis produtivos de mitate a este respecto é a tradición das «oito vistas dos ríos Xiao e Xiang» (Xiao-Xiang bajing 潚湘八景 en chinés, pronunciado Shô-Shô hakkei en xaponés). Esta tradición, que ten a súa orixe no século XI nas obras de Song Di, pintor da dinastía Song do Norte, foi introducida máis tarde no Xapón, onde consistía en ver certos lugares de beleza panorámica «como se» fosen as seis escenas orixinais da China Central -por exemplo «gansos salvaxes pousándose nun banco de area», "veleiros retornando a unha baía afastada», "campá da noite dun templo na néboa», etc. ${ }^{10}$. Moitos lugares do Xapón acabaron por ser vistos deste xeito, como «as oito vistas de Ômi» (Ômi hakkei, no lago Biwa), malia que, en realidade, eran moi diferentes das paisaxes orixinais dos ríos Xiang e Xiao. Por moi diferentes que fosen, e mesmo sendo consciente desa diferenza, o que se valoraba das oito vistas de Ômi era velas «como se» fosen as orixinais.

Queda claro, daquela, que a representación non é o que importa. A mitate non consiste nunha semellanza obxectiva, é o proceso en si de «ver como», que supón unha participación activa do observador na «institución da realidade».

\section{ARTIALIZACIÓN E REALIDADE TANXIBLE}

Nos casos anteriores, mitate encádrase no ámbito da estética. É un xogo estético. Pero, cales son os límites deste xogo?

No sentido máis restrinxido, a estética está relacionada co fermoso. Pero sábese que, en orixe, a palabra grega aisthêsis significaba a facultade de sentir. Foi a partir desta ampla acepción cando Platón falou do mundo tanxible (kosmos aisthêtos), é dicir, a realidade que podemos percibir a través dos sentidos -fronte a to noêton (o intelixible). Isto implica que o eido da estética non é

${ }^{10}$ Para máis referencias, véxase Haga, 1987. 
outra cousa que o eido do sentir (aisthanomai), é dicir, o eido das sensacións e percepcións, que é moito máis extenso que o que adoitamos ter en mente cando falamos sobre a estética.

O problema da paisaxe é que está relacionada tanto coa acepción restrinxida como coa acepción ampla do estético. Diríase que, en xeral, os xeógrafos se ocupan desta mentres que os historiadores da arte e os esteticistas o fan daquela. De feito, os xeógrafos xaponeses non lle puxeron nunca moita atención á cuestión da mitate, que, en cambio, é un tema transcendental para a estética en sentido estrito.

A este respecto, o punto de mira da mesoloxía está enfocado, precisamente, cara á ambigüidade da paisaxe. Na miña experiencia persoal como xeógrafo, descubrir a idea da mitate fíxome repensar progresivamente en toda a cuestión do medio humano e, xa que logo, na da propia realidade. O certo é que, ao principio, o problema parecía limitarse á paisaxe no seu sentido restrinxido -o da historia da arte. Pero, mesmo neste eido, non se podía ignorar que a estética, como rama da filosofía que é, tiña un ámbito de estudo máis amplo, xa que non só se ocupa da beleza da paisaxe como representación -sobre todo na pintura-, senón tamén da propia natureza ou do ambiente, o que, loxicamente, deu lugar ao eido propio da xeografía: a relación das sociedades humanas coa Terra.

No meu caso, esta relación entre a paisaxe como representación -unha obra de arte- e a paisaxe como o que é representado -o ambiente- xurdiu despois de ler a tese de Alain Roger, publicada en 1978 co título Nus et paysages. Essai sur la fonction de l'art. Esta tese xira arredor do concepto de «artialización", é dicir, o efecto da arte na nosa relación coa natureza, que nos fai percibir o ambiente como algo fermoso -efecto in visu- e tamén actúa materialmente sobre este para facelo fermoso -efecto in situ- a través de modelos creados pola arte.

Lin esta tese con especial interese porque, con influencias de La Production de l'espace, de Henri Lefebvre (Lefebvre, 1974), a miña propia investigación sobre o Xapón se convertera nunha busca das relacións analóxicas que vinculan historicamente, nun medio humano, os aspectos mental, social e físico do espazo para conformar una espacialidade específica. Eu xa estaba convencido de que existe un nexo entre a paisaxe in visu e a paisaxe in situ, pero foi na tese de Roger onde atopei unha interpretación filosófica explícita deste asunto, que casaba perfectamente coa miña propia interpretación gradualmente elaborada desa 
mesoloxía que Watsuji defendera; con todo, faltaba aplicala alén dos seus escritos impresionistas e, máis tarde, deterministas sobre fûdo.

\section{MEDIANZA E TRAXECCIÓN}

Fûdo, de Watsuji (Watsuji, 1935), comeza coa seguinte oración: «O obxecto desta obra é explicar fûdosei 風土生 como momento estrutural da existencia humana (ningen sonzai no kôzô keiki 人間存在の構造契機)». Nas versións inglesa e alemá do libro non se traduciu o concepto fûdose ${ }^{11}$. Eu acabei por traducilo polo neoloxismo «medianza» (médiance) ${ }^{12}$ polos dous motivos que expoño a continuación. Primeiro, porque se axustaba á miña tradución de fûdo por milieu en francés -cuxa raíz latina é med, ou meso en grego, de aí: mésologie por fúdogaku. E segundo e principal, porque se axustaba á definición do termo do propio Watsuji. «Momento» (keiki 契機) debe entenderse aquí como unha relación dinámica entre os dous aspectos do ser humano segundo Watsuji ${ }^{13}$ : o

${ }^{11} \mathrm{Na}$ tradución de Geoffrey Bownas, Climate. A philosophical study (1960), que cambiou de título a Climate and culture. A philosophical study en 1988, fûdosei tradúcese indiferentemente por "climate, the function of climate, human climate», etc. ('clima, a función do clima, o clima humano'); na tradución de Dora Fischer-Barnicol e Okochi Ryôgi, Fudo. Der Zusammenhang zwischen Klima und Kultur, de 1992, tradúcese por «Klima, das Klimatische, das Klimatisch Bestimmtsein», etc. ('clima, o climático, a determinación climática'). En ningunha destas dúas traducións se distingue entre fûdo e fûdosei, malia que en xaponés estas dúas palabras son tan distintas como, por exemplo, historia e historicidade ou local e localización en galego. Na versión inglesa, a primeira oración é «My purpose in this study is to clarify the function of climate as a factor within the structure of human existence»; e na alemá é «In der vorliegenden Studie möchten wir zeigen, daß fûdosei, das Klimatische, zur Struktur des menschlichen Dasein gehört». A oración orixinal en xaponés éこの書の目ざすところは人間存在の構造 契機としての風土性を明らかにすることである. Existe unha tradución ao chinés, Feng$t u$, de 2006, que non resulta moi útil, pois os conceptos esenciais de Watsuji adoitan traducirse cos mesmos sinogramas e, por outro lado, o tradutor, Chen Liwei, carece de toda consistencia e coherencia filosóficas. Na devandita tradución, a primeira oración queda reducida a: «Ben shu zhi zai chanming ren de cunzai fangshi yu fengtu de guanxi» ('O obxecto deste libro é explicar as formas en que os seres humanos se relacionan co medio'). Na miña opinión, a mellor tradución dispoñible é a castelá, de Juan Masiá e Anselmo Mataix, Antropología del paisaje. Climas, culturas y religiones (Salamanca, Sígueme, 2006). Eles traduciron fûdosei por «ambientalidad». Con todo, a súa tradución da primeira oración non transmite a definición de Watsuji deste concepto: «El objeto de esta obra es resaltar la importancia de la ambientalidad -clima y paisaje- como elemento estructural de la existencia humana».

12 Que acuñei en 1985 (Berque, 1986).

13 Todos os devanditos tradutores pasaron por alto o concepto de «momento», que tanto lles gustaba aos filósofos xaponeses da época e que tomaron de Hegel, quen, asemade, o tomara da mecánica. 
individuo, por un lado (bito 人), e un conxunto de relacións (chamado aidagara 間柄), polo outro, tanto entre as persoas como entre as persoas e o seu ambiente. Do latín medietas (metade), médiance designa esta relación dinámica entre as nosas dúas «metades» ontolóxicas.

A idea de que o ser humano non se pode reducir a un cogito individual procede en Europa, como mínimo, de Hegel, e xera finalmente o concepto de intersubxectividade. A postura de Watsuji, influenciada polo concepto de Ausser-sich-sein (estar fóra dun mesmo) de Heidegger, forma parte desta tradición. Non obstante, para un xeógrafo coma min, a súa perspectiva hermenéutica non era concluínte. Eu precisaba dunha base más sólida e positivista para converter a medianza no fundamento da mesoloxía. E atopeina na interpretación de Leroi-Gourhan (Leroi-Gourhan, 1964) da aparición da especie humana, segundo a cal os nosos ancestrais simios se tornaron humanos exteriorizando as funcións do «corpo animal» a un «corpo social» constituído por sistemas técnicos e simbólicos. Ao meu ver, este corpo social exteriorizado era a manifestación concreta do absolutamente humano Ausser-sich-sein do Dasein, é dicir, a ex-sistencia humana. Pois ben, dado que os nosos sistemas técnicos e simbólicos forzosamente afectan o ambiente, eu tiña que estender este corpo social -que é tecno-simbólico- para convertelo nun «corpo medial» eco-tecno-simbólico, o que me permitiu definir a medianza como a relación dinámica -o momento- entre as nosas dúas «metades» ontolóxicas: o noso corpo animal e o noso corpo medial, é dicir, o noso medio.

Este momento especificamente humano non se pode producir unicamente a través da exteriorización, segundo afirma Leroi-Gourhan (Leroi-Gourhan, 1964), xa que o resultado apenas sería unha proxección dualista clasicamente moderna do suxeito humano sobre o ambiente como obxecto. A medianza é moito máis que iso. Esta supón non só unha proxección do corpo animal nun medio, senón tamén unha retroproxección dese medio -o corpo medial- no corpo animal. Este movemento de ida e volta é o que eu denomino «traxección» (Berque, 1986).

Máis concretamente, a traxección significa que a nosa corporalidade se proxecta a través dos nosos sistemas técnicos ao medio, que estes antropizan, ao tempo que o noso medio é humanizado polos nosos sistemas simbólicos, é 
dicir, transcende o noso corpo animal na forma de conexións neurais -representacións, etc.-, as cales lle dan sentido e valor. Estas conexións teñen a súa orixe no feito de que os sistemas técnicos proveñen das funcións do mesmo corpo animal. Xa que logo, ao seren exteriorizados -como sistemas de ferramentas, etc.- tamén permanecen "presentes» no interior do corpo animal, onde «representan» o que se exteriorizou -o corpo medial. Correlativamente, o transcendemento do corpo medial ao corpo animal tamén se manifesta en forma de cambios somáticos ${ }^{14}$.

En resumo, como seres humanos, no mesmo proceso de traxección, as técnicas «cosmizan» o noso corpo e convérteno na nosa mundanidade, e os símbolos «somatizan» o noso mundo e convérteno na nosa corporalidade.

Así é como eu entendo a relación entre in visu e in situ na realidade da paisaxe. Igual que a realidade, a paisaxe é traxectiva, é dicir, atópase dentro e fóra de nós e incorpora o suxeito e o obxecto na «traxectividade da realidade».

\section{COSMICIDADE E REALIDADE}

No canto do concepto de Entweltlichung (desmundanización) de Heidegger, prefiro dicir décosmisation (descosmización) para designar o proceso asociado ao dualismo moderno: a división entre un universo exterior e obxectivado, por unha banda, e o mundo interior do suxeito individual moderno, pola outra. De feito, o que se perdeu nesta dicotomía foi xustamente esa unidade do cosmos

\footnotetext{
${ }^{14}$ A curto prazo, esta somatización pode observarse, por exemplo, nos efectos da maxia en moitas sociedades -como causar doenzas ou mesmo a morte. A longo prazo, vén a representar precisamente a tese de Leroi-Gourhan, segundo a cal o corpo dun simio evolucionou ata converterse no do Homo sapiens a través dos efectos de retroalimentación do desenvolvemento de sistemas técnicos e simbólicos. Con todo, e moi contraditoriamente, Leroi-Gourhan só fala dunha exteriorización destes sistemas, quedando así encadrado no dualismo moderno. Esta mesma contradición, aínda que por razóns completamente distintas, atopámola en Heidegger, quen fala, asemade, de "estar fóra dun mesmo» (Ausser-sich-sein), o que vai alén do dualismo moderno, e de "estar cara á morte» (sein zum Tode), o que, como subliñou Watsuji, se limita ao horizonte do suxeito individual moderno. Dito doutro xeito, malia iren alén do paradigma moderno nalgúns aspectos, ambos os dous pensadores quedan enmarcados neste nalgúns outros aspectos. A «medianza» humana fai que o ser humano "estea cara á vida» (sei e no sonzai), como escribiu Watsuji. Mutatis mutandis, esta idea xa está presente no principio de Zong Bing e tamén a expresan simbolicamente a maioría das relixións humanas.
} 
premoderno que foi aseverada ao final do Timeo: «E agora declaremos que o noso discurso sobre o Todo (peri tou Pantos) alcanzou a súa fin. Tras recibir todos os seres vivos, mortais e inmortais, e encherse desta maneira, ser vivente visible (zôon horaton) que comprende todos os seres vivos visibles, imaxe (eikôn) tanxible do deus (theos aisthêtos) intelixible (to noêton), o maior, o mellor, o máis fermoso e perfecto, naceu o Mundo (ho Kosmos): é o Ceo (Ouranos), que é un (heis) e único no seu xénero (monogenês)».

Aínda que Platón establece aquí, asemade, a devandita distinción entre o tanxible e o intelixible, que daría lugar posteriormente ao dualismo moderno, o seu máximo interese, dado que estas liñas constitúen a conclusión da súa ontocosmoloxía máis explícita, cómpre destacar a seguinte identidade: Pan=Kosmos $=$ Ouranos. Noutras palabras: o Todo, o Mundo e o Universo son a mesma cousa.

Con todo, esta unidade practicamente desapareceu en Europa tras a revolución copernicana. Desde aquela, a realidade divídese entre o obxectivo, por un lado, e o subxectivo, polo outro; unha división que mesmo foi medida por Newton en Opticks, en 1704. E a partir de alí, o mundo occidental impuxo progresivamente na Terra este POMC -paradigma occidental moderno-clásico-, onde o obxectivo é o real e o subxectivo, unha ilusión.

Volvendo a Uexküll, esta división equivale a dicir que só o Umgebung é real, mentres que o Umwelt é unha ilusión. De feito, isto é exactamente o que un discípulo de Uexküll, Hidaka (Hidaka, 2003), manifesta cando, no subtítulo dunha obra sobre o Umwelt da bolboreta da col, afirma que «sen ilusión non é posible ver o mundo». Así e todo, esta postura -a do POMC- é contraditoria. $\mathrm{O}$ feito de que a bolboreta vexa os raios ultravioleta e o ser humano non o faga non é unha ilusión subxectiva, senón unha realidade fisiolóxica obxectiva. Xa que logo, a realidade do Umwelt dunha bolboreta non é igual que a dun ser humano malia que ambos os dous habitan o mesmo Umgebung. Posto que os seres vivos só poden vivir se teñen un Umwelt específico, dicir que só o Umgebung é real equivale a afirmar que toda a biosfera está baseada na ilusión, o que, obviamente, resulta absurdo.

É evidente que o POMC resulta ineficaz neste caso. Temos que admitir que existen distintos niveis e diversos tipos de realidade, mesmo no eido das ciencias naturais. E con máis razón se pode dicir isto verbo das culturas humanas, pois 
cada unha delas ten o seu propio mundo malia que están baseadas nun único Umwelt humano, exactamente igual que todos os distintos Umwelten respectivos das especies de seres vivos -incluído o ser humano- están baseados nun único Umgebung -a Terra, ou a biosfera.

O que quero dicir é que, en cada nivel ontolóxico -o da biosfera e o da ecúmene-, na realidade se combina unitariamente unha base universal -un universo- cun mundo particular. É dicir, no tocante á vida -incluída a humana-, a realidade é unha cuestión de cosmicidade. Non é ese obxecto totalmente universal, neutro e exterior que, segundo o POMC, é o único real.

\section{A COSMOFANÍA DA REALIDADE}

Daquela, cal é o proceso que institúe un medio humano específico (Umwelt concreto) baseado no ambiente (Umgebung abstracto)?

Contra finais dos anos oitenta, seguindo unha corrente xeográfica clásica, eu chegara á conclusión de que a realidade dun medio está composta por varias prises médiales (conexións mediais ou potencialidades affordances) que se poden clasificar en catro categorías: recursos, tensións, riscos e servizos. Estas conexións mediais son inherentes ao ser humano, non existen per se como obxectos absolutos. Por exemplo, o petróleo, como combustible, é un recurso, pero para selo foi necesario inventar o vehículo de motor. Xa que logo, as conexións mediais, é dicir, as da paisaxe como servizo, son continxentes e históricas, aínda que comportan necesariamente a existencia dunha base universal e non histórica no ambiente.

Máis tarde, esta cuestión reduciuse á natureza daquilo que, a través das conexións mediais, institúe "como» a realidade dun medio humano. Por exemplo, considerar o petróleo "como" un combustible ou considerar o ambiente "como» unha paisaxe. Ou ben, xa no nivel da biosfera e da evolución, que constitúen a base universal da ecúmene e da historia, considerar unha lonxitude de onda electromagnética de $700 \mathrm{~nm}$ «como» vermella, o que fai o ollo humano, pero non o dunha vaca.

Neste punto comecei a decatarme de que a natureza deste proceso estaba relacionada dalgún xeito co xogo da mitate. Non obstante, eu non dispuña dos 
instrumentos ontolóxicos e antropolóxicos necesarios para desenvolver esta intuición. Descubrinos nos anos seguintes, combinando catro referencias bibliográficas fundamentais: Spiel als Weltsymbol ( $O$ xogo como simbolo do mundo, de Eugen Fink, de 1960; Sein und Zeit (Ser e tempo) e Ursprung des Kunstwerkes ( $A$ orixe da obra de arte), de Martin Heidegger, de 1927 e 1935, respectivamente; Basho (Lugar, 1927), de Nishida Kitarô, de 1927; e Le Geste et la parole (O xesto e a palabra), de André Leroi-Gourhan, de 1964.

$\mathrm{Na}$ obra de Nishida atopei a idea de que o mundo é un predicado (jutsugo 述 語), o que, visto desde a perspectiva xeográfica, significaba para min que é a maneira en que a humanidade interpreta a Terra a través das súas propias conexións mediais, é dicir, os seus sistemas eco-tecno-simbólicos -dito doutro xeito, como sentimos, pensamos e facemos as cousas na Terra. Nas obras de Heidegger e Leroi-Gourhan atopei as claves que me permitiron comprender por fin a definición de medianza de Watsuji, o que me levou a definila como a combinación estrutural dos nosos corpos animal e medial. Por outra banda, Fink axudoume a comprender a continxencia de todo iso: como nun xogo, tanto a ecúmene como a historia poderían ser distintas se tivesen outras regras, ou sexa, outros predicados xurdidos continxentemente -outros mundos-; e este xogo era a «loita» (Streit) entre a Terra e o mundo que Heidegger considera o principio do Ser ou, desde a perspectiva mesolóxica, o inicio da ecúmene como relación entre a Terra e o mundo humano.

Estas ideas, que se materializaron nos noventa, leváronme a elaborar unha teoría da ecúmene (Berque, 2000) que, en liñas xerais, se pode representar coa seguinte fórmula: $\mathrm{R}=\mathrm{S} / \mathrm{P}^{15}$; onde $\mathrm{R}$ é a realidade, $\mathrm{S}$ o suxeito $-\mathrm{o}$ universo, a Terra ou o Umgebung- e P o predicado - un mundo ou Umwelt. Esta fórmula lese así: a realidade é $S$ considerado como P. Dado que isto é moito máis que unha predicación no seu sentido habitual, tamén se pode ler así: a realidade é a cosmofanía de $S$ como P; ou mesmo: a realidade é a traxección de $S$ como $P$.

Seguindo esta lóxica, esta é tamén a esencia da mitate, e da paisaxe en xeral. No caso concreto da mitate, esta significa: ver un ambiente dado $S$-por exemplo a beira do lago Biwa- como se fose unha referencia cultural dada P -por

15 Presentei esta teoría no simposio Shizen to iu bunka no shatei ( $O$ alcance da cultura como natureza), Universidade de Quioto, Departamento de Filosofía, 2 de decembro de 2002; e máis tarde publiqueina (Berque, 2003). 
exemplo un cadro de Song Di. No caso da paisaxe, esta significa: a cosmofanía do ambiente $S$ como unha paisaxe $\mathrm{P}$.

Isto xera a realidade dun medio $\mathrm{S} / \mathrm{P}$ como o noso, que se pode caracterizar polo feito, entre outros, de percibirmos o noso ambiente $S$ como unha paisaxe P. En cambio, se fósemos, por exemplo, kukatja do deserto occidental australiano, percibiriamos o noso ambiente $S$ como unha manifestación do Tjukurrpa P, que os lagartos brancos (kartiya) traduciron por «tempo dos soños» (dreamtime) e que, definitivamente, non é sinónimo de "paisaxe» (Poirier, 1996).

Segundo os testemuños atopados, esta cosmofanía que a "paisaxe» caracteriza apareceu por primeira vez na dinastía Jin oriental, no Pavillón das Orquídeas -Lanting, en Zhejiang, preto da actual Shaoxing-, onde o famoso calígrafo Wang Xizhi reuniu os seus amigos para un banquete o terceiro día do mes lunar de Yonghe IX (353 d. de C.). Como adoitaba acontecer entre a nobreza daquel tempo, isto incluía xogar a un xogo literario chamado «copa que leva a corrente nun regato serpeante» (liu shang qu shui 流觞曲水). Este xogo consistía en escribir un dístico antes de que unha copa de viño, que ía flotando polo regato que atravesaba o xardín, chegase ata onde un estaba. Nalgúns dos poemas que se escribiron nesta ocasión atopamos indicios de que, por vez primeira no que se ía converter no noso mundo, estes distinguidos convidados estaban a «gozar do seu ambiente como unha paisaxe» ${ }^{16}$.

${ }^{16}$ Para máis detalles sobre este banquete, véxase Obi, 1988, p. 113 e ss. 


\section{BIBLIOGRAFÍA}

Agamben, G.: L'Aperto. L'uomo e l'animale, Torino, Bollati Boringhieri, 2002.

Berque, A.: Le Sauvage et l'artifice. Les Japonais devant la nature, Paris, Gallimard, 1986, e Japan. Nature, artifice and Japanese culture, Yelvertoft Manor, Pilkington Press, 1997.

BERQUE, A. (ed.): Actes du colloque franco-japonais sur la recherche paysagère, Tokyo, Maison franco-japonaise, 1987.

BERQUe, A.: Les Raisons du paysage. De la Chine antique aux environnements de synthèse, Paris, Hazan, 1995.

BERQUe, A.: "Cosmophanie ou paysage», en D. GUILlaud et al.: Le Voyage inachevé... À Joël Bonnemaison, Paris, ORSTOM/PRODIG, 1998, p. 741-744.

BERQUe, A.: Écoumène. Introduction à l'étude des milieux humains, Paris, Belin, 2000.

BERQUE, A.: «Shizen to iu bunka (A cultura como natureza)», en E. KIHEI (ed.): Shizen to iu bunka no shatei (O Alcance da cultura como natureza), Kyôto, Kyôto Daigaku daigakuin bungaku kenkyûka, 2003, p. 7-23.

Berque, A.: "Cosmofanía y paisaje moderno", en J. Maderuelo (ed.): Paisaje y pensamiento, Madrid, Abada Editores, 2006, p. 187-207.

BerQUe, A.: El pensamiento paisajero, Madrid, Biblioteca Nueva, 2009.

Delahaye, H.: Les Premières peintures de paysage en Chine, aspects religieux, Paris, École française d'Extrême-orient, 1981.

EsCANDE, Y.: Montagnes et eaux. La culture du shanshui, Paris, Hermann, 2005.

FinK, E.: Spiel als Weltsymbol, Stuttgart, Kohlhammer, 1960.

GLACKEN, C. J.: Traces on the Rhodian shore. Nature and culture in Western thought from Ancient Times to the end of the eighteenth century, Berkeley, Los Angeles, London, University of California Press, 1967. [Hai edición en castelán].

Gotô, A. et al:: Shigo no imêji. Tôshi wo yomu tame ni (As imaxes do léxico poético. Para ler a poesía chinesa), Tokyo, Tôhô Shoten, 2000.

HAGA, T.: «Landscape in cross-cultural perspective: from Hsiao-Hsiang to the Eight Views of Omi», en A. BERQUe (ed.): Actes..., op. cit., p. 115-123.

Heidegger, M.: Sein und Zeit, Tübingen, Niemeyer, 1927. [Hai edición en castelán].

HeidegGer, M.: «Ursprung des Kunstwerkes», Holzwege, Frankfurt/Main, Klostermann, 1949. [Hai edición en castelán].

HIDAKA, T.: Dôbutsu to ningen no sekai ninshiki (Cognición do mundo entre os humanos e os animais), Tokyo, Chikuma, 2003.

KIHEI, E. (ed.): Shizen to iu bunka no shatei (O Alcance da cultura como natureza), Kyôto, Kyôto Daigaku daigakuin bungaku kenkyûka, 2003.

Lefebvre, H.: La Production de l'espace, Paris, Anthropos, 1974.

Leroi-Gourhan, A.: Le Geste et la parole, Paris, Albin Michel, vol. 2, 1964.

Maderuelo, J.: El Paisaje. Genealogía de un concepto, Madrid, Abada Editores, 2005.

Maderuelo, J. (ed.): Paisaje y pensamiento, Madrid, Abada Editores, 2006.

NAKAmURA, Y.: Fûkeigaku nyûmon (Introdución ao estudo da paisaxe), Tokyo, Chuokoron, 1982.

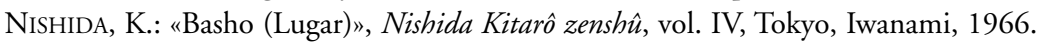

OвI, K.: Sha Reiun. Kodoku no sansui shijin (Xie Lingyun. O poeta paisaxistico solitario), Tokyo, Kyûko shoin, 1983. 
OBI, K.: Chûgoku no inton shisô (O pensamento eremita en China), Tokyo, Chûo kôron, 1988.

POIRIER, S.: Les Jardins du nomade. Cosmologie, territoire et personne dans le désert occidental australien, Münster, LIT Verlag, 1996.

RiTTER, J.: Landschaft. Zur Funktion der Aesthetischen in der modernen Gesellschaft, 1963, na tradución francesa Paysage. Fonction de l'esthétique dans la société moderne, Besançon, les Editions de l'Imprimeur, 1977. [Hai edición en castelán].

Roger, A.: Nus et paysages. Essai sur la fonction de l'art, Paris, Aubier, 1978.

TaChibana No Toshitsuna: Sakuteiki (Notas sobre a arte dos xardíns), Ikeda, Nihon zôen sekkei jimusho Kansai shibu, 1977.

Veblen, T.: Theory of the leisure class, 1899, na tradución francesa Théorie de la classe de loisir, Paris, Gallimard, 1970. [Hai edición en castelán].

VON UeXKÜlL, J.: Streifzüge durch die Umwelten von Tieren und Menschen, Berlin, J. Springer, 1934.

Williams, R.: The Country and the city, Oxford, Oxford University Press, 1973. [Hai edición en castelán]. 